\title{
Determinação do teor de carboidratos em minicepas de Eucalyptus benthamii
}

\section{Determination of the carbohydrates content in Eucalyptus benthamii mini-stumps}

\author{
Gilvano Ebling Brondani ${ }^{*}$, Jonathan Max Emilian Hoffmann ${ }^{2}$, Antônio Natal Gonçalves ${ }^{1} \mathrm{e}$ \\ Marcílio de Almeida ${ }^{3}$
}

\begin{abstract}
${ }^{I}$ Departamento de Ciências Florestais, Escola Superior de Agricultura "Luiz de Queiroz"/Universidade de São Paulo - ESALQ/USP; 13.418-900; Piracicaba - SP - Brasil. ${ }^{2}$ Departamento de Ciências Florestais, Universidade Federal do Paraná - UFPR, 80.210-170, Curitiba - PR - Brasil. ${ }^{3}$ Departamento de Ciências Biológicas, Escola Superior de Agricultura "Luiz de Queiroz"/Universidade de São Paulo - ESALQ/USP; 13.418-900; Piracicaba - SP - Brasil. *Parte da Tese de Doutorado apresentada ao PPG em Recursos Florestais da ESALQ/USP.
\end{abstract}

\begin{abstract}
The aim of this study was to evaluate the foliar content of soluble carbohydrates non-structural of Eucalyptus benthamii mini-stumps regarding to $\mathrm{Zn}$ and $\mathrm{B}$ concentrations during successive shoot collections. Shoots were collected from mini-stumps fertigated with nutrient solutions containing different $\mathrm{Zn}$ and B concentrations $(S 1$ - free of Zn and B, S2 - $0.5 \mathrm{mg} \mathrm{L}^{-1} \mathrm{Zn}, \mathrm{S3}-0.5 \mathrm{mg} \mathrm{L}^{-1} \mathrm{~B}, \mathrm{S4}-0.5 \mathrm{mg} \mathrm{L}^{-1} \mathrm{Zn}$ and B, S5 - $1.0 \mathrm{mg} \mathrm{L}^{-1} \mathrm{Zn}$ and B, S6 - $2.0 \mathrm{mg}$ $L^{-1} Z n$ and B). Eight shoot collection of the clonal mini-garden were performed. The content total of soluble carbohydrates non-structural of leaves (sucrose, glucose and fructose) was determined in the $2^{\text {nd }}, 4^{\text {th }}, 6^{\text {th }}$ and $8^{\text {th }}$ shoot collections. The increasing of the $\mathrm{Zn}$ and $\mathrm{B}$ concentrations in the nutrient solution induced reduction of the total content of soluble carbohydrates non-structural of leaves, and the fructose was the most affected.
\end{abstract}

Key-words: Nutritive solution, fertigation, mini-cutting technique, glucose, fructose, sucrose

\section{INTRODUÇÃO}

O Eucalyptus benthamii é uma importante espécie para a composição de plantios florestais, principalmente ao considerar a sua tolerância a temperaturas mais baixas e a geadas (Jovanovic e Booth, 2002; Mujiu et al., 2003; Paludzyszyn Filho et al., 2006). Contudo, a multiplicação clonal dessa espécie por meio das técnicas de estaquia (Graça et al., 1999) e miniestaquia (Brondani et al., 2010a; Wit Ondas et al., 2009) não é viável comercialmente até o momento, devido aos baixos índices de enraizamento, sendo necessárias pesquisas na área de biotecnologia visando aumentar os índices de produção de mudas clonais.

As condições nutricionais da minicepa influenciam a rizogênese de propágulos (Alfenas et al., 2004;
Hartmann et al., 2011; Kratz et al., 2011; Taiz e Zeiger, 2009), a qual é dependente da interação entre os fatores endógenos e exógenos (Corrêa et al., 2005; Li et al., 2009; Brondani et al., 2010b; Brondani et al., 2010c; Brondani et al., 2012). Dentre os elementos que podem influenciar a rizogênese de propágulos destacam-se o $\mathrm{Zn}$ e B (Kersten et al., 1993; Malta et al., 2002; Scalon et al., 2003), os quais podem ser aplicados via fertirrigação em concentrações controladas em sistemas de minijardins clonais.

Outro aspecto a ser considerado, refere-se aos carboidratos, como a sacarose, glicose e frutose, os quais representam papel crucial para 0 metabolismo, crescimento e morfogênese das plantas, principalmente pelo fornecimento de energia e carbono para a biossíntese de

Author for correspondence: gebrondani@yahoo.com.br 
aminoácidos (Pavlinova et al., 2002; Stenvall et al., 2009; Veyres et al., 2008). O acúmulo de carboidratos nos tecidos foliares das plantas também pode variar em relação à época do ano (Kersten et al., 1993; Mindêllo Neto, 2005), fatores edáficos e também de acordo com os tratos culturais (Borba et al., 2005), os quais podem ser exemplificados no sistema de poda contínua de brotações em minijardins clonais de Eucalyptus. Além disso, nas plantas, existe forte interação do nível de carboidratos com o nível hormonal endógeno (Agulló-Antón et al., 2011), afetando desta forma, o processo morfogênico e/ou organogênico (Coruzzi e Zhou, 2001; Komatsu et al., 2011; Kumar et al., 1999; Stenvall et al., 2009; Veyres et al., 2008). A falha na competência de um tecido pode refletir na falta de receptores para a classe de regulador de crescimento que irá induzir o processo organogênico (MacArthur et al., 2009; Papp e Plath, 2011; Smet e Beeckman, 2011), sendo que a inativação de reguladores de crescimento pode ocorrer por meio da conjunção de açúcares derivados da hidrólise da sacarose, glicose e frutose, alterando o balanço das moléculas ativas de auxina e citocinina (AgullóAntón et al., 2011; Coruzzi e Zhou, 2001).

Devido a função no metabolismo das plantas, os carboidratos podem influenciar a produção de brotações e o posterior enraizamento em propágulos (Hartmann et al., 2011), sejam provenientes da estaquia, miniestaquia ou da microestaquia. Contudo, não existem relatos quanto a determinação de carboidratos em tecidos foliares de minicepas de Eucalyptus benthamii manejadas em minijardim clonal visando a produção de brotações com qualidade adequada para o emprego das técnicas de clonagem.

Com base no exposto, o presente trabalho teve como objetivo determinar os teores foliares de carboidratos solúveis não estruturais (glicose, frutose e sacarose) de minicepas de Eucalyptus benthamii em relação as coletas de brotações e concentrações de Zn e B.

\section{MATERIAL E MÉTODOS}

\section{Constituição do minijardim clonal}

As unidades experimentais foram compostas por mudas clonais de Eucalyptus benthamii Maiden \& Cambage (clones BP101, BP118 e BP120) propagadas pelo processo de miniestaquia com aplicação de $2.000 \mathrm{mg} \mathrm{L}^{-1}$ de AIB e cultivadas em vasos plásticos $(18 \times 16 \times 45 \mathrm{~cm})$ com duas aberturas na porção inferior (Figura $1 \mathrm{~A})$. O substrato foi composto por areia, fração fina $(0,10$ $\mathrm{mm}<$ diâmetro de partícula $<0,25 \mathrm{~mm}$ ), o qual foi peneirado (peneira de malha $3 \mathrm{~mm}$ ), lavado com água deionizada por cinco vezes e autoclavado durante 20 minutos a $121^{\circ} \mathrm{C}\left(\approx 1,0 \mathrm{kgf} \mathrm{cm}^{-2}\right)$, a fim de erradicar plantas daninhas e patógenos, como fungos e bactérias. Previamente ao plantio das mudas nos vasos, procedeu-se a lavagem do sistema radicial das mudas com água deionizada durante 10 minutos, com a finalidade de lixiviar nutrientes e demais componentes aderidos. Os vasos foram suspensos por grades metálicas a 85 $\mathrm{cm}$ do solo, sendo plantadas seis mudas por vaso no espaçamento $10 \times 8 \mathrm{~cm}$, os quais foram compostos por seis mudas dispostas sequencialmente. Após sete dias efetuou-se a quebra do caule das mudas a $10 \mathrm{~cm}$ acima da porção basal, com a finalidade de reduzir a dominância apical e favorecer o crescimento de brotações axilares, as quais foram emitidas aos 21 dias após a quebra do caule (Figura 1 B). Para a formação das minicepas, foi realizada poda da parte aérea a $7 \mathrm{~cm}$ acima da base da muda, aos 15 dias após a quebra do caule, conforme metodologia descrita por Brondani (2008), constituindo o minijardim clonal em sistema de vaso (Figura $1 \mathrm{C}-\mathrm{D})$.

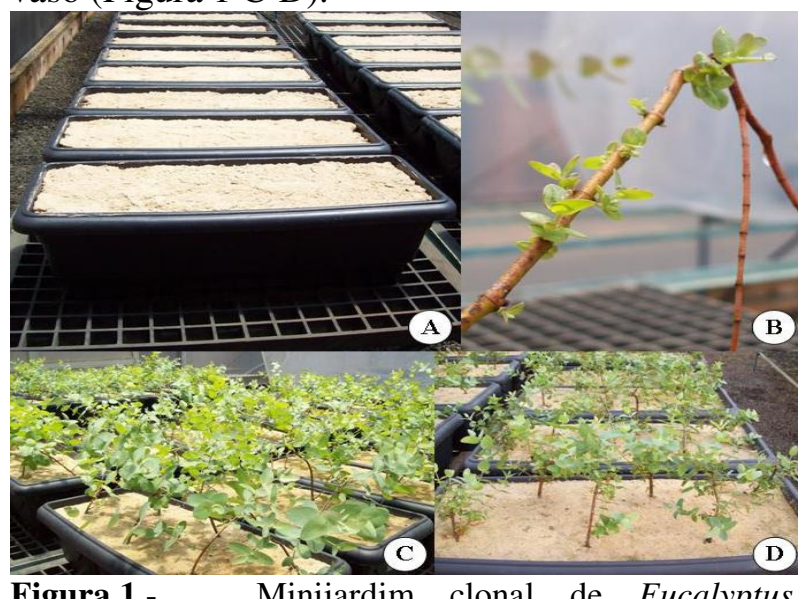

benthamii. (A) detalhe do vaso contendo areia fina; (B) detalhe da indução de brotações axilares pela quebra do caule aos 21 dias; (C) disposição dos vasos contendo as minicepas aos 50 dias; (D) minicepas emitindo brotações aptas para a coleta aos 50 dias.

\section{Manejo das minicepas}

O minijardim clonal foi instalado em condições de casa de vegetação recoberta com polietileno 
transparente e composta por dois sistemas de ventiladores, sendo que os dados da temperatura do ar foram coletados diariamente visando uma possível correlação com as variáveis respostas. A cada sete dias adicionou-se $100 \mathrm{~mL}$ de solução nutritiva básica por minicepa (Tabela 1), sendo realizada irrigação com água deionizada diariamente, visando suprir a perda excessiva por evapotranspiração. A cada semana foi realizada lavagem da areia com água deionizada para evitar o excesso de salinização.

Tabela 1. Composição da solução nutritiva básica para a fertirrigação do minijardim clonal de Eucalyptus benthamii.

\begin{tabular}{|c|c|c|}
\hline Nutriente & & $\begin{array}{c}\text { Solução Nutritiva } \\
\left(\mathrm{mg} \mathrm{L}^{-1}\right)\end{array}$ \\
\hline $\mathrm{N}-\mathrm{NO}_{3}{ }^{-}$ & & 60,00 \\
\hline $\mathrm{N}-\mathrm{NH}_{4}^{+}$ & & 30,00 \\
\hline $\mathrm{P}$ & & 12,00 \\
\hline $\mathrm{Ca}$ & & 40,00 \\
\hline $\mathrm{K}$ & & 80,00 \\
\hline S & & 10,00 \\
\hline $\mathrm{Mg}$ & & 12,00 \\
\hline $\mathrm{Cu}$ & & 0,10 \\
\hline $\mathrm{Fe}$ & & 2,00 \\
\hline Mo & & 0,02 \\
\hline $\mathrm{Mn}$ & & 1,60 \\
\hline Fonte de Macro e Micronutriente & $\mathrm{FQ} / \mathrm{PM}$ & $\left(\mathrm{mg} \mathrm{L}^{-1}\right)$ \\
\hline Nitrato de potássio $\left(\right.$ Nuclear $\left.^{\circledR}\right)$ & $\mathrm{KNO}_{3} / 101,10$ & 206,85 \\
\hline Monoamônio fostato (Mallinckrodt ${ }^{\circledR}$ ) & $\mathrm{NH}_{4} \mathrm{H}_{2} \mathrm{PO}_{4} / 115,03$ & 44,57 \\
\hline Nitrato de amônio $\left(\right.$ Reagex $\left.^{\circledR}\right)$ & $\mathrm{NH}_{4} \mathrm{NO}_{3} / 80,04$ & 140,50 \\
\hline Cloreto de cálcio $\left(\right.$ Synth $\left.^{\circledR}\right)$ & $\mathrm{CaCl}_{2} \cdot 2 \mathrm{H}_{2} \mathrm{O} / 147,02$ & 111,13 \\
\hline Nitrato de cálcio (Labsynth ${ }^{\circledR}$ ) & $\mathrm{Ca}\left(\mathrm{NO}_{3}\right)_{2} \cdot 4 \mathrm{H}_{2} \mathrm{O} / 236,15$ & 57,18 \\
\hline Cloreto de magnésio $\left(\right.$ Synth $\left.^{\circledR}\right)$ & $\mathrm{MgCl}_{2} \cdot 6 \mathrm{H}_{2} \mathrm{O} / 203,30$ & 50,46 \\
\hline Sulfato de magnésio (Mallinckrodt ${ }^{\circledR}$ ) & $\mathrm{MgSO}_{4} .7 \mathrm{H}_{2} \mathrm{O} / 246,48$ & 60,49 \\
\hline Sulfato de manganês (Ecibra $\left.{ }^{\circledR}\right)$ & $\mathrm{MnSO}_{4} \cdot \mathrm{H}_{2} \mathrm{O} / 169,01$ & 4,9223 \\
\hline Sulfato de cobre (Mallinckrodt ${ }^{\circledR}$ ) & $\mathrm{CuSO}_{4} .5 \mathrm{H}_{2} \mathrm{O} / 249,68$ & 0,3929 \\
\hline Sulfato de ferro $\left(\right.$ Synth $\left.^{\circledR}\right)$ & $\mathrm{FeSO}_{4} .7 \mathrm{H}_{2} \mathrm{O} / 278,02$ & 9,9520 \\
\hline Sódio - EDTA (Nuclear $\left.{ }^{\circledR}\right)$ & $\mathrm{Na}_{2}$-EDTA. $2 \mathrm{H}_{2} \mathrm{O} / 372,24$ & 13,3110 \\
\hline Molibdato de sódio (Merck ${ }^{\circledR}$ ) & $\mathrm{Na}_{2} \mathrm{MoO}_{4} \cdot 2 \mathrm{H}_{2} \mathrm{O} / 241,95$ & 0,0504 \\
\hline
\end{tabular}

${ }^{*} \mathrm{O} \mathrm{pH}$ foi ajustado para 6,2 a $25^{\circ} \mathrm{C}$ com ácido clorídrico $(\mathrm{HCl})$ ou hidróxido de sódio $(\mathrm{NaOH})$, ambos a $1 \mathrm{M} . \mathrm{FQ}=$ fórmula química, $\mathrm{PM}=$ peso molecular.

Tratamentos e delineamento experimental

Como tratamentos foram aplicados diferentes concentrações de zinco $(\mathrm{Zn})$ e boro (B), os quais foram fornecidos por meio de solução nutritiva (Tabela 2). 
Tabela 2. Combinação das concentrações de Zn e B para a composição das soluções nutritivas.

\begin{tabular}{ccc}
\hline Solução Nutritiva & $\mathrm{Zn}^{(1)}\left(\mathrm{mg} \cdot \mathrm{L}^{-1}\right)$ & $\mathrm{B}^{(2)}\left(\mathrm{mg} \cdot \mathrm{L}^{-1}\right)$ \\
\hline $\mathrm{S} 1$ & 0,0 & 0,0 \\
$\mathrm{~S} 2$ & 0,5 & 0,0 \\
$\mathrm{~S} 3$ & 0,0 & 0,5 \\
$\mathrm{~S} 4$ & 0,5 & 0,5 \\
$\mathrm{~S} 5$ & 1,0 & 1,0 \\
$\mathrm{~S} 6$ & 2,0 & 2,0 \\
\hline (1) Fornecido na forma de sulfato de zinco (Mallinckrodt $\left.{ }^{\circledR} / \mathrm{ZnSO}_{4} \cdot \mathrm{HH}_{2} \mathrm{O} / 287,54\right)$. & ${ }^{(2)}$ Fornecido na forma de ácido \\
bórico (Ecibra &
\end{tabular}

O experimento foi conduzido com base na solução nutritiva apresentada na Tabela 1 , variando somente as concentrações dos elementos $\mathrm{Zn}$ e B de acordo com as combinações apresentadas na Tabela 2. A cada sete dias adicionou-se $100 \mathrm{~mL}$ da solução nutritiva (Tabelas 1 e 2) por minicepa (Figura 1 C-D). O experimento foi conduzido durante 12 meses, sendo realizadas oito coletas sucessivas de brotações com intervalos variando de 21 a 35 dias. Teor foliar de carboidratos solúveis não
estruturais

$\mathrm{O}$ experimento foi conduzido no delineamento inteiramente casualizado em arranjo fatorial $(4 \times 6)$ com parcelas subdivididas no tempo, sendo os fatores constituídos por quatro coletas de brotações $\left(2^{\mathrm{a}}, 4^{\mathrm{a}}, 6^{\mathrm{a}}\right.$ e $8^{\mathrm{a}}$ coletas $)$ e seis combinações de Zn e B (Tabela 2), com três repetições. As amostras foram constituídas de folhas totalmente expandidas do terço superior da brotação (folhas apicais), sendo que após a coleta, todas as folhas foram lavadas com água deionizada. Para a determinação dos teores foliares de carboidratos solúveis não estruturais (sacarose, frutose e glicose), as folhas foram armazenadas em congelador a $-80^{\circ} \mathrm{C}$. Os extratos foram obtidos a partir de $160 \mathrm{mg}$ (peso fresco) dos tecidos vegetais congelados. As amostras foram cortadas (tamanho de $1 \mathrm{~mm}^{2}$ ) e fervidas em banho maria (10 minutos) seguida de centrifugação ( 3 minutos a 16.000 RPM) e, por fim, as amostras foram filtradas (filtro descartável Millex - $\mathrm{GP}^{\circledR}$ com membrana estéril de 0,45 $\mu \mathrm{m}$ ) com o uso de uma seringa de $10 \mathrm{~mL}$. Após a filtragem, as alíquotas (eluato) foram completadas a $5 \mathrm{~mL}$ e então efetuou-se a leitura dos teores dos carboidratos. O eluato foi analisado por cromatografia de íons IC5000 (Dionex, 2000), usando um detector eletroquímico. Os carboidratos foram separados usando uma coluna analítica Carbo PAC PA100 DIONEX, equipado com uma coluna guarda. Os padrões de glicose, frutose e sacarose $\left(\operatorname{Sigma}^{\circledR}\right)$ foram utilizados para determinar as concentrações dos carboidratos (Dionex, 2000; Veyres et al., 2008).

\section{Análise estatística dos dados}

Os dados mensurados de todos os experimentos foram submetidos ao teste de Hartley $(P<0,05)$ e Lilliefors $(P<0,05)$ e transformados quando necessário. Em seguida, foi realizada análise de variância (ANOVA, $P<0,01$ e $P<0,05$ ). De acordo com a significância da ANOVA, os dados dos fatores qualitativos foram comparados pelo teste de Tukey $(P<0,05)$.

\section{RESULTADOS}

De acordo com a análise de variância houve interação entre a coleta de brotações e solução nutritiva para o teor foliar de sacarose, glicose e total de carboidratos solúveis não estruturais contidos em minicepas de Eucalyptus benthamii. $\mathrm{O}$ teor foliar de frutose variou significativamente apenas em relação a solução nutritiva, independente da coleta de brotações (Tabela 3). 
Tabela 3. Resumo da análise de variância para o teor foliar de sacarose (SAC), glicose (GLI), frutose (FRU) e total de carboidratos solúveis não estruturais (TOTAL) em brotações de minicepas de Eucalyptus benthamii em relação à coleta de brotações e concentrações de $\mathrm{Zn}$ e B.

\begin{tabular}{lccccc}
\hline $\begin{array}{c}\text { Causas da } \\
\text { Variação }\end{array}$ & GL & $\begin{array}{c}\mathrm{SAC}^{(1)} \\
\left(\mathrm{mg} \mathrm{g}^{-1}\right)\end{array}$ & $\begin{array}{c}\mathrm{GLI}^{(1)} \\
\left(\mathrm{mg} \mathrm{g}^{-1}\right)\end{array}$ & $\begin{array}{c}\mathrm{FRU}^{(1)} \\
\left(\mathrm{mg} \mathrm{g}^{-1}\right)\end{array}$ & $\begin{array}{c}\mathrm{TOTAL}^{(1)} \\
\left(\mathrm{mg} \mathrm{g}^{-1}\right)\end{array}$ \\
\hline Coleta (COL) & 3 & $0,9361^{* *}$ & $0,1388^{\mathrm{ns}}$ & $0,3928^{\mathrm{ns}}$ & $0,1426^{\mathrm{ns}}$ \\
Resíduo-COL & 8 & $0,0727^{\mathrm{ns}}$ & $0,0733^{* *}$ & $0,1052^{\text {ns }}$ & $0,0861^{\mathrm{ns}}$ \\
Parcela & 11 & - & - & - & - \\
Solução-SOL & 5 & $0,2288^{* *}$ & $0,0515^{\mathrm{ns}}$ & $0,1661^{*}$ & $0,0931^{\mathrm{ns}}$ \\
COL*SOL & 15 & $0,2288^{* *}$ & $0,0607^{* *}$ & $0,0877^{\mathrm{ns}}$ & $0,0885^{*}$ \\
Resíduo & 40 & 0,0465 & 0,0215 & 0,0620 & 0,0397 \\
Subparcela & 71 & - & - & - & - \\
Média & - & 0,12 & 3,57 & 5,51 & 9,21 \\
CV $_{\text {exp. }}(\%)$ & - & 37,26 & 16,69 & 14,24 & 8,88 \\
\hline ns & - & & &
\end{tabular}

${ }^{n s}$ Valor não significativo ao nível de 5\% de probabilidade de erro pelo teste $\mathrm{F}$. * e ${ }^{* *}$ Valor significativo ao nível de $5 \%$ e $1 \%$ de probabilidade de erro, respectivamente pelo teste $\mathrm{F} .{ }^{(1)}$ Dados transformados por $\log (n+0,5)$, onde $n=$ dado amostrado. $\mathrm{GL}=$ graus de liberdade, $\mathrm{CV}_{\text {exp. }}=$ coeficiente de variação experimental, TOTAL corresponde ao somatório de sacarose, glicose e frutose.

O teor foliar de frutose diferiu significativamente entre as soluções S1 e S6, apresentando valores de

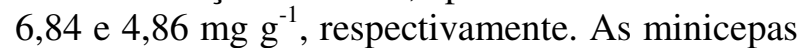
que receberam o tratamento com solução $\mathrm{S} 1$ (isento de $\mathrm{Zn}$ e B) apresentaram cerca de $40 \%$ a mais de teor foliar de frutose em relação às minicepas que receberam a solução S6 (maior concentração de Zn e B). As soluções S2, S3, S4 e S5 não apresentaram diferença significativa do teor foliar de frutose em relação as demais soluções nutritivas (Tabela 4).

Tabela 4. Teor foliar de frutose (FRU) em brotações de minicepas de Eucalyptus benthamii em relação à solução de Zn e B.

\begin{tabular}{cc}
\hline Solução & $\begin{array}{c}\text { FRU } \\
\left(\mathrm{mg} \mathrm{g}^{-1}\right)\end{array}$ \\
\hline S1 & $6,84 \pm 1,74 \mathrm{~A}$ \\
S2 & $5,37 \pm 2,13 \mathrm{AB}$ \\
S3 & $5,49 \pm 2,00 \mathrm{AB}$ \\
S4 & $5,09 \pm 1,65 \mathrm{AB}$ \\
S5 & $5,43 \pm 1,27 \mathrm{AB}$ \\
S6 & $4,86 \pm 1,97 \mathrm{~B}$ \\
\hline
\end{tabular}

Nas colunas, médias seguidas por mesma letra, não diferem significativamente pelo teste de Tukey ao nível de $5 \%$ de probabilidade de erro. Dados apresentados como: média \pm desvio padrão.

Ao analisar os teores foliares de sacarose verificase que os valores foram reduzidos em relação a solução nutritiva e coleta de brotações (Tabela 5). Apenas na $8^{\text {a }}$ coleta de brotações foi detectada a presença de teor foliar de sacarose nas brotações das minicepas de Eucalyptus benthamii, onde o maior acúmulo ocorreu para as minicepas que foram submetidas as soluções S5 $\left(1,54 \mathrm{mg} \mathrm{g}^{-1}\right)$ e S6 (1,02 $\left.\mathrm{mg} \mathrm{g}^{-1}\right)$, as quais não diferiram significativamente. Considerando a $8^{\mathrm{a}}$ coleta de brotações, os menores teores foliares de sacarose foram verificados para as soluções S1, S2, S3 e $\mathrm{S} 4$, as quais não diferiram significativamente (Tabela 5).

Considerando cada coleta de brotações, o teor foliar de glicose das minicepas de Eucalyptus benthamii não variou significativamente em relação as soluções nutritivas avaliadas. Contudo, ao comparar as coletas de brotações dentro de cada solução nutritiva, pode-se verificar variação significativa do teor foliar de glicose para as soluções S2 e S4. A solução S2 apresentou 
diferença significativa entre a $4^{\mathrm{a}}$ e $8^{\mathrm{a}}$ coleta de brotações, sendo determinado 4,50 e $2,49 \mathrm{mg} \mathrm{g}^{-1}$ de glicose, respectivamente. Ao considerar a solução S4, pode-se observar diferença significativa entre a $4^{\mathrm{a}}$ e $2^{\mathrm{a}}$ coleta de brotações, apresentando 4,71 e 2,59 $\mathrm{mg} \mathrm{g}^{-1}$ de glicose, respectivamente (Tabela 5).

$\mathrm{O}$ teor foliar total de carboidratos solúveis não estruturais (somatório dos teores foliares de sacarose, frutose e glicose) apresentou diferença significativa tanto ao considerar as coletas de brotações dentro das soluções nutritivas, quanto ao considerar as soluções nutritivas dentro das coletas de brotações (Tabela 5). Durante a $2^{\mathrm{a}}$ coleta de brotações o maior valor do teor total de carboidrato ocorreu para as soluções S1 $(11,73 \mathrm{mg}$ $\left.\mathrm{g}^{-1}\right)$ e $\mathrm{S} 2\left(11,29 \mathrm{mg} \mathrm{g}^{-1}\right)$, as quais não diferiram significativamente. $\mathrm{Na} 4^{\text {a }}$ coleta de brotações $\mathrm{O}$ maior valor do teor total de carboidrato ocorreu para as soluções $\mathrm{S} 1\left(12,12 \mathrm{mg} \mathrm{g}^{-1}\right)$ e $\mathrm{S} 4(12,10 \mathrm{mg}$ $\left.\mathrm{g}^{-1}\right)$, que não diferiram significativamente. $\mathrm{Na}^{\mathrm{a}}$ coleta de brotações verifica-se que o maior valor do teor total de carboidrato ocorreu nas soluções S3 $\left(9,76 \mathrm{mg} \mathrm{g}^{-1}\right)$ e S5 $\left(9,26 \mathrm{mg} \mathrm{g}^{-1}\right)$, que não diferiram significativamente. $\mathrm{Na} 8^{\mathrm{a}}$ coleta de brotações o maior valor do teor total de carboidrato foi registrado para as soluções S1 $\left(9,44 \mathrm{mg} \mathrm{g}^{-1}\right)$ e $\mathrm{S} 5\left(9,86 \mathrm{mg} \mathrm{g}^{-1}\right)$, as quais apresentaram diferença significativa em relação as demais soluções nutritivas.

Tabela 5. Teor foliar de sacarose (SAC), glicose (GLI) e total de carboidratos solúveis não estruturais (TOTAL) em brotações de minicepas de Eucalyptus benthamii em relação a coleta de brotações e solução de Zn e B.

\begin{tabular}{|c|c|c|c|c|c|c|}
\hline \multirow{3}{*}{ Coleta } & \multicolumn{6}{|c|}{ Solução } \\
\hline & S1 & $\mathrm{S} 2$ & S3 & $\mathrm{S} 4$ & S5 & S6 \\
\hline & \multicolumn{6}{|c|}{$\mathrm{SAC}$} \\
\hline $2^{a}$ & $0,00 \pm 0,00 \mathrm{Aa}$ & $0,00 \pm 0,00 \mathrm{Aa}$ & $0,00 \pm 0,00 \mathrm{Aa}$ & $0,00 \pm 0,00 \mathrm{Aa}$ & $0,00 \pm 0,00 \mathrm{Ba}$ & $0,00 \pm 0,00 \mathrm{Ba}$ \\
\hline $4^{\mathrm{a}}$ & $0,00 \pm 0,00 \mathrm{Aa}$ & $0,00 \pm 0,00 \mathrm{Aa}$ & $0,00 \pm 0,00 \mathrm{Aa}$ & $0,00 \pm 0,00 \mathrm{Aa}$ & $0,00 \pm 0,00 \mathrm{Ba}$ & $0,00 \pm 0,00 \mathrm{Ba}$ \\
\hline $6^{\mathrm{a}}$ & $0,00 \pm 0,00 \mathrm{Aa}$ & $0,00 \pm 0,00 \mathrm{Aa}$ & $0,00 \pm 0,00 \mathrm{Aa}$ & $0,00 \pm 0,00 \mathrm{Aa}$ & $0,00 \pm 0,00 \mathrm{Ba}$ & $0,00 \pm 0,00 \mathrm{Ba}$ \\
\hline $8^{a}$ & $0,00 \pm 0,00 \mathrm{Ab}$ & $0,00 \pm 0,00 \mathrm{Ab}$ & $0,12 \pm 0,21 \mathrm{Ab}$ & $0,22 \pm 0,38 \mathrm{Ab}$ & $1,54 \pm 0,88 \mathrm{Aa}$ & $1,02 \pm 0,89 \mathrm{Aa}$ \\
\hline Coleta & \multicolumn{6}{|c|}{ GLI } \\
\hline $2^{a}$ & $3,27 \pm 0,60 \mathrm{Aa}$ & $4,28 \pm 1,19 \mathrm{ABa}$ & $3,29 \pm 1,03 \mathrm{Aa}$ & $2,59 \pm 0,62 \mathrm{Ba}$ & $2,80 \pm 0,56 \mathrm{Aa}$ & $3,05 \pm 0,35 \mathrm{Aa}$ \\
\hline $4^{a}$ & $4,49 \pm 0,69 \mathrm{Aa}$ & $4,50 \pm 0,94 \mathrm{Aa}$ & $3,47 \pm 1,24 \mathrm{Aa}$ & $4,71 \pm 0,87 \mathrm{Aa}$ & $3,98 \pm 0,44 \mathrm{Aa}$ & $3,15 \pm 0,50 \mathrm{Aa}$ \\
\hline $6^{\mathrm{a}}$ & $3,37 \pm 0,89 \mathrm{Aa}$ & $4,03 \pm 0,97 \mathrm{ABa}$ & $3,85 \pm 0,46 \mathrm{Aa}$ & $3,68 \pm 0,15 \mathrm{ABa}$ & $3,93 \pm 0,38 \mathrm{Aa}$ & $2,77 \pm 0,36 \mathrm{Aa}$ \\
\hline $8^{\mathrm{a}}$ & $3,77 \pm 0,60 \mathrm{Aa}$ & $2,49 \pm 0,33 \mathrm{Ba}$ & $3,77 \pm 0,43$ Aa & $3,45 \pm 0,62 \mathrm{ABa}$ & $3,82 \pm 0,84 \mathrm{Aa}$ & $3,14 \pm 0,58 \mathrm{Aa}$ \\
\hline Coleta & \multicolumn{6}{|c|}{ TOTAL } \\
\hline $2^{a}$ & $11,73 \pm 1,71 \mathrm{Aa}$ & $11,29 \pm 3,46 \mathrm{Aa}$ & $8,25 \pm 2,08 \mathrm{Bc}$ & $6,49 \pm 1,59 \mathrm{Dd}$ & $8,31 \pm 1,31 \mathrm{Cc}$ & $9,93 \pm 3,39 \mathrm{Ab}$ \\
\hline $4^{\mathrm{a}}$ & $12,12 \pm 1,75 \mathrm{Aa}$ & $10,90 \pm 2,81 \mathrm{Ab}$ & $9,76 \pm 5,24 \mathrm{Ac}$ & $12,10 \pm 0,74 \mathrm{Aa}$ & $10,40 \pm 1,32 \mathrm{Ab}$ & $7,34 \pm 1,00 \mathrm{Bd}$ \\
\hline $6^{\mathrm{a}}$ & $8,99 \pm 1,82 \mathrm{Bbc}$ & $8,92 \pm 2,17 \mathrm{Bbc}$ & $9,76 \pm 0,98 \mathrm{Aa}$ & $8,62 \pm 0,95 \mathrm{Bc}$ & $9,26 \pm 0,71 \mathrm{Bab}$ & $7,44 \pm 1,59 \mathrm{Bd}$ \\
\hline $8^{a}$ & $9,44 \pm 1,94 \mathrm{Ba}$ & $5,67 \pm 0,28 \mathrm{Cd}$ & $8,73 \pm 1,63 \mathrm{Bb}$ & $7,82 \pm 1,15 \mathrm{Cc}$ & $9,86 \pm 1,48 \mathrm{ABa}$ & $7,86 \pm 2,14 \mathrm{Bc}$ \\
\hline
\end{tabular}

Nas colunas, médias seguidas por mesma letra maiúscula e, nas linhas, médias seguidas por mesma letra minúscula não diferem significativamente pelo teste de Tukey ao nível de 5\% de probabilidade de erro. TOTAL corresponde ao somatório de sacarose, glicose e frutose. Dados apresentados como: média \pm desvio padrão.

Ao analisar a variação do teor total de carboidrato solúvel não estrutural em relação a cada solução nutritiva, verifica-se que as soluções S1 e S2 apresentaram os maiores valores durante a $2^{\mathrm{a}}$ e $4^{\mathrm{a}}$ coletas de brotações, sendo registrada redução do teor total de carboidrato até a $8^{\mathrm{a}}$ coleta de brotações. A solução S3 apresentou o maior valor do teor total de carboidrato durante a $4^{\mathrm{a}}$ e $6^{\mathrm{a}}$ coletas de brotações, as quais não diferiram significativamente. Em relação a solução S4, o maior valor do teor total de carboidrato ocorreu somente na $4^{\mathrm{a}}$ coleta de brotações. Em relação a solução S5 o maior valor do teor total de carboidrato ocorreu na $4^{\mathrm{a}}$ e $8^{\mathrm{a}}$ coletas de brotações. A solução S6 apresentou o maior valor do teor total de carboidrato somente na $2^{\mathrm{a}}$ coleta de brotações (Tabela 5). Em termos gerais, com o aumento das concentrações de $\mathrm{Zn}$ e B na solução nutritiva ocorreu redução dos teores foliares de 
carboidratos solúveis não estruturais, sendo que a frutose foi a mais afetada.

\section{DISCUSSÃO}

Os carboidratos são importantes fontes de energia e carbono estrutural para o metabolismo vegetal, regulando reações bioquímicas para a manutenção do crescimento e desenvolvimento vegetal (Corrêa et al., 2005; Pavlinova et al., 2002; Stenvall et al., 2009; Taiz e Zeiger, 2009; Veyres et al., 2008). Além disso, existem evidências de uma forte interação do teor de carboidratos com o nível hormonal endógeno, sendo que esse efeito está diretamente relacionado com o processo morfogênico e/ou organogênico (Coruzzi e Zhou, 2001; Komatsu et al., 2011). Adicionalmente, o enraizamento em propágulos demanda consumo de energia, e o manejo do minijardim clonal visando adequar os teores de carboidratos na planta matriz se torna essencial para a obtenção de resultados satisfatórios durante a clonagem de genótipos selecionados (Agulló-Antón et al., 2011; Ragonezi et al., 2010; Xavier et al., 2009).

A solução nutritiva isenta de $\mathrm{Zn}$ e B (S1) induziu maior acúmulo de frutose nos tecidos foliares das minicepas de Eucalyptus benthamii, indicando uma correlação da nutrição mineral com o acúmulo dessa forma de carboidrato nos tecidos foliares apicais. Resultado semelhante foi reportado por Leite et al. (2008) que verificaram aumento do teor foliar de arabinose na ausência de boro para Eucalyptus grandis. Contudo, em outro estudo, a suplementação de B na solução nutritiva induziu aumento do acúmulo dos teores foliares de manitol e sorbitol para Eucalyptus grandis $\mathrm{x}$ Eucalyptus urophylla e Eucalyptus grandis (Leite et al., 2010), sendo que os autores sugerem estreita correlação do elemento B com a síntese de carboidratos específicos e a sua mobilidade na planta.

Os teores reduzidos de sacarose eram esperados, tendo em vista as amostras foliares serem oriundas da ponteira (meristema apical) das brotações das minicepas de Eucalyptus benthamii. Nessas regiões meristemáticas a atividade metabólica é mais elevada (regiões fisiologicamente ativas), sendo comum ocorrer formas de carboidratos mais reduzidos que são utilizados como fontes energéticas para as diversas reações bioquímicas, como a frutose e glicose (Veyres et al., 2008). O carboidrato na forma de sacarose apresenta mobilidade na planta, sendo facilmente translocado para outras regiões de crescimento não-fotossintetizantes, como caule e raiz (Mindêllo Neto, 2005) onde geralmente, apresenta-se em maior concentração (Taiz e Zeiger, 2009).

O teor de foliar de glicose não variou em relação as soluções nutritivas, contudo a maior diferença ocorreu entre as épocas de amostragem. Esse resultado está de acordo com o relatado para diversas espécies de plantas, onde o acúmulo de carboidrato varia em relação aos efeitos da sazonalidade ao longo do ano (Kersten et al., 1993; Mindêllo Neto, 2005). Além disso, o manejo de poda do minijardim clonal também pode ter contribuído para ocasionar alterações dos teores de carboidratos (Borba et al., 2005). Nesse sentido, Torres (2003) observou que as brotações mais aptas para o emprego da miniestaquia estão diretamente relacionadas ao aumento dos níveis de carboidratos de acordo com a época do ano e do intervalo entre as coletas de brotações. $\mathrm{O}$ autor salienta que o aumento da periodicidade entre as coletas de brotações resulta no aumento da área foliar específica, permitindo assim, maior produção de fotoassimilados, incrementando os teores endógenos de carboidratos.

Em termos gerais, os teores foliares dos carboidratos solúveis não estruturais (glicose, frutose e sacarose) para as minicepas de Eucalyptus benthamii foram afetados pelas soluções nutritivas e coletas de brotações ao longo do tempo, e os valores assemelharam-se aos reportados para estudos in vitro com Eucalyptus grandis, o qual apresentou variação de 5,50 a $14,90 \mathrm{mg} \mathrm{g}^{-1}$ em diferentes meios de cultura (Correia, 2006), para Eucalyptus urophylla, que apresentou variação de 6,9 a $11,7 \mathrm{mg} \mathrm{g}^{-1} \mathrm{em}$ relação a diferentes concentrações de boro (Trevisam, 2001) e para Eucalyptus urophylla que variou de 2,2 a 12,2 $\mathrm{mg} \mathrm{g}^{-1}$ em relação a diferentes concentrações de boro e cálcio (Trevisam, 2005).

Outros efeitos em relação ao acúmulo de carboidratos também podem estar relacionados as variações da temperatura. Floriani et al. (2011) verificaram correlação negativa entre a elevada temperatura com a concentração de carboidratos solúveis totais no tecido foliar de Eucalyptus dunnii, bem como, correlação com a tolerância ao frio com o aumento do acúmulo de carboidrato. Os autores sugeriram que a determinação da concentração foliar de carboidratos solúveis totais em mudas de Eucalyptus dunnii pode ser característica quantitativa a ser considerada na seleção de espécies tolerantes ao frio em 
programas de melhoramento. Futuros estudos poderão demonstrar a aplicabilidade desse efeito para o Eucalyptus benthamii em termos de sua tolerância a baixas temperaturas, tendo em vista que os efeitos em nível fisiológico na propagação clonal de plantas com as interações entre os teores de carboidratos, hormônios, nutrientes, bem como, fatores ambientais como luz e temperatura, não estão totalmente compreendidos (Hartmann et al., 2011; Ragonezi et al., 2010).

\section{CONCLUSÕES}

O teor foliar de sacarose, glicose e total de carboidratos solúveis não estruturais em minicepas de Eucalyptus benthamii variaram em relação a coleta de brotações e solução nutritiva. O teor foliar de frutose variou somente em relação a solução nutritiva.

Em termos gerais, com o aumento das concentrações de $\mathrm{Zn}$ e $\mathrm{B}$ na solução nutritiva ocorreu redução dos teores foliares totais de carboidratos solúveis não estruturais, sendo que a frutose foi a mais afetada.

\section{AGRADECIMENTOS}

À FAPESP (Fundação de Amparo à Pesquisa do Estado de São Paulo) e CAPES (Coordenação de Aperfeiçoamento de Pessoal de Nível Superior) pelo suporte financeiro. À Planflora Mudas Florestais pela disponibilização dos materiais genéticos de Eucalyptus benthamii. Os autores também agradecem ao José Roberto Romanini e ao Fabrício Augusto Hansel pelo suporte laboratorial.

\section{RESUMO}

Objetivou-se avaliar os teores foliares de carboidratos solúveis não estruturais de minicepas de Eucalyptus benthamii em relação a diferentes concentrações de $\mathrm{Zn}$ e B ao longo de sucessivas coletas de brotações. As brotações foram oriundas de minicepas fertirrigadas com soluções nutritivas variando nas concentrações de $\mathrm{Zn}$ e B (S1 - isento de $\mathrm{Zn}$ e B, S2 - 0,5 $\mathrm{mg} \mathrm{L}^{-1}$ de $\mathrm{Zn}$, $\mathrm{S} 3-0,5 \mathrm{mg} \mathrm{L}^{-1}$ de B, S4 - 0,5 $\mathrm{mg} \mathrm{L}^{-1}$ de Zn e B, S5 $1,0 \mathrm{mg} \mathrm{L}^{-1}$ de Zn e B, S6 - 2,0 $\mathrm{mg} \mathrm{L}^{-1}$ de Zn e B), sendo realizadas oito coletas de brotações do minijardim clonal. $\mathrm{O}$ teor foliar total de carboidratos solúveis não estruturais (sacarose, glicose e frutose) foi determinado na $2^{\mathrm{a}}, 4^{\mathrm{a}}, 6^{\mathrm{a}}$ e $8^{\mathrm{a}}$ coletas de brotações. $\mathrm{O}$ aumento das concentrações de $\mathrm{Zn}$ e B na solução nutritiva reduziu os teores foliares totais de carboidratos solúveis não estruturais, sendo a frutose a mais afetada.

Palavras-chave: Solução nutritiva, fertirrigação, miniestaquia, glicose, frutose, sacarose

\section{REFERÊNCIAS}

Agulló-Antón, M. A.; Sánchez-Bravo, J.; Acosta, M.; Druege, U. (2011), Auxins or sugars: what makes the difference in the adventitious rooting of stored carnation cuttings? Journal of Plant Growth Regulation, 30, 100-113.

Alfenas, A. C.; Zauza, E. A. V.; Mafia, R. G.; Assis, T. F. (2004), Clonagem e doenças do eucalipto. Viçosa: Editora UFV, 442p.

Borba, M. R. C.; Scarpare Filho, J. A.; Kluge, R. A. (2005), Teores de carboidratos em pessegueiros submetidos a diferentes intensidades de poda verde em clima tropical. Revista Brasileira de Fruticultura, 27, 68-72.

Brondani, G. E. Miniestaquia e micropropagação de Eucalyptus benthamii Maiden \& Cambage $\mathrm{x}$ Eucalyptus dunnii Maiden. Dissertação (Mestrado em Engenharia Florestal) - Universidade Federal do Paraná, 2008.

Brondani, G. E.; Gonçalves, A. N.; Almeida, M. Determinação do tempo ótimo de enraizamento para miniestacas de Eucalyptus benthamii Maiden \& Cambage (2010a), In: REUNIÓN ARGENTINA DE FISIOLOGÍA VEGETAL, 28., 2010, La Plata. Libro de Resúmenes... La Plata: Asociación Sociedad Argentina de Fisiología Vegetal, 194p.

Brondani, G. E.; Grossi, F.; Wendling, I.; Dutra, L. F.; Araujo, M. A. (2010b), Aplicação de IBA para o enraizamento de miniestacas de Eucalyptus benthamii Maiden \& Cambage $\mathrm{x}$ Eucalyptus dunnii Maiden. Acta Scientiarum. Agronomy, 32, 667-674.

Brondani, G. E.; Wendling, I.; Grossi, F.; Dutra, L. F.; Araujo, M.A. (2010c), Miniestaquia de Eucalyptus benthamii $\times$ Eucalyptus dunnii: ( II ) sobrevivência e enraizamento de miniestacas em função das coletas e estações do ano. Ciência Florestal, 20, 453-465.

Brondani, G. E.; Wendling, I.; Brondani, A. E.; Araujo, M. A.; Silva, A. L. L.; Gonçalves, A. N. (2012), Dynamics of adventitious rooting in minicuttings of Eucalyptus benthamii x Eucalyptus dunnii. Acta Scientiarum. Agronomy, 34, 169-178. 
Corrêa, L. R.; Paim, D. C.; Schwambach, J.; FettNeto, A. G. (2005), Carbohydrates as regulatory factors on the rooting of Eucalyptus saligna Smith and Eucalyptus globulus Labill. Plant Growth Regulation, 45, 63-73.

Correia, D. Macronutrientes, aspectos nutricionais e bioquímicos no crescimento de brotações de Eucalyptus grandis in vitro. Tese (Doutorado em Recursos Florestais) - Escola Superior de Agricultura "Luiz de Queiroz", Universidade de São Paulo, 2006.

Coruzzi, G. M. e Zhou, L. (2001), Carbon and nitrogen sensing and signaling in plants: emerging 'matrix effects'. Current Opinion in Plant Biology, 4, 247-53.

Dionex (2000), Analysis of carbohydrates by high performance anion exchange chromatography with pulsed amperometric detection (HPAE-PAD). Atlanta: Dionex. 14 p. (DIONEX. Technical Note, 20).

Floriani, M. M. P.; Steffens, C. A.; Chaves, D. M. (2011), Rustificação de plantas de Eucalyptus dunnii Maiden e a relação entre as concentrações de carboidratos solúveis totais e de prolina foliar e a tolerância ao frio. Revista Árvore, 35, 21-29.

Graça, M. E. C.; Shimizu, J. Y.; Tavares, F. R. (1999), Capacidade de rebrota e de enraizamento de Eucalyptus benthamii. Boletim de Pesquisa Florestal, 39, 135-138.

Hartmann, H. T.; Kester, D. E.; Davies Jr, F. T.; Geneve, R. L. (2011), Plant propagation: principles and practices. 8 Ed. São Paulo: PrenticeHall, 915p.

Jovanovic, T.; Booth, T. H. (2002), Improved species climatic profiles. Australia: Union Offset Printing, Joint Venture Agroforestry Program, Rural Industries Research and Development Corporation, 68p.

Kersten, E.; Lucchesi, A. A.; Gutierrez, L. E. (1993), Efeitos do boro e zinco no teor de carboidratos solúveis, aminoácidos totais e no enraizamento de estacas de ramos de ameixeira (Prunus salicina Lindl.). Scientia Agricola, 50, 1318.
Komatsu, Y. H.; Batagin-Piotto, K. D.; Brondani, G. E.; Gonçalves, A. N.; Almeida, M. (2011), In vitro morphogenic response of leaf sheath of Phyllostachys bambusoides. Journal of Forestry Research, 22, 209-215.

Kratz, D.; Wendling, I.; Brondani, G. E. (2011), Concentrações de ácido indolbutírico no enraizamento de Cryptomeria japonica. Journal of Biotechnology and Biodiversity, 2, 14-21.

Kumar, A.; Sood, A.; Palni, L. M. S.; Gupta, A. K. (1999), In vitro propagation of Gladiolus hybridus Hort.: synergistic effect of heat shock and sucrose on morphogenesis. Plant Cell, Tissue and Organ Culture, 57, 105-112.

Leite, S. M. M.; Marino, C. L.; Bonine, C. A. V. (2010), Respostas de clones de Eucalyptus grandis e E. grandis x E. urophylla à supressão de boro. Scientia Forestalis, 38, 19-25.

Leite, S. M. M.; Valle, C. F.; Bonine, C. A. V.; Marino, C. L. (2008), Boron influence on concentration of polyols and other sugars in Eucalyptus. Revista Árvore, 32, 815-820.

Li, S. W.; Xue, L.; Xu, S.; Feng, H.; An, L. (2009), Mediators, genes and signaling in adventitious rooting. The Botanical Review, 75, 230-247.

MacArthur, B. D.; Ma'ayan, A.; Lemischka, I. R. (2009), Systems biology of stem cell fate and cellular reprogramming. Nature Reviews Molecular Cell Biology, 10, 672-681.

Malta, M. R.; Furtini Neto, A. E.; Alves, J. D.; Guimarães, P. T. G. (2002), Efeito da aplicação de zinco via foliar na síntese de triptofano, aminoácidos e proteínas solúveis em mudas de cafeeiro. Brazilian Journal of Plant Physiology, 14, 31-37.

Mindêllo Neto, U. R. (2005), Enraizamento de estacas de pessegueiro em função do uso de ácido indolbutírico e fertilizante orgânico. Revista Brasileira de Fruticultura, 27, 92-94.

Mujiu, L.; Arnold, R.; Bohai, L.; Minsheng, Y. Selection of cold-tolerant eucalypts for Hunan Province (2003), In: Turnbull, J.W. (Ed.). Eucalypts in Asia: proceedings of a international 
conference held in Zhanjiang, Guangdong, people's Republic of China. Canberra: Elect Printing. p. 107-116. (ACIAR. Proceedings, 111). Paludzyszyn Filho, E.; Santos, P. E. T.; Ferreira, C. A. (2006), Eucaliptos indicados para plantio no Estado do Paraná. Colombo: Embrapa Florestas. (EMBRAPA. Documentos, 129), 45p.

Papp, B.; Plath, K. (2011), Reprogramming to pluripotency: stepwise resetting of the epigenetic landscape. Cell Research, 21, 486-501.

Pavlinova, O. A.; Balakhontsev, E. N.; Prasolova, M. F.; Turkina, M. V. (2002), Sucrose-phosphate synthase, sucrose synthase, and invertase in sugar beet leaves. Russian Journal of Plant Physiology, 49, 68-73.

Ragonezi, C.; Klimaszewska, K.; Castro, M. R.; Lima, M.; Oliveira, P.; Zavattieri, M. A. (2010), Adventitious rooting of conifers: influence of physical and chemical factors. Trees - Structure and Function, 24, 975-992.

Scalon, S. P. Q.; Ramos, M. B. M.; Vieira, M. C. (2003), Auxinas e boro no comprimento da maior raiz e número de estacas enraizadas de guaco (Mikania glomerata Sprengel), alecrim (Rosmarinus officinalis L.) e carqueja (Baccharis trimera Less A.P.D.C.) em duas épocas de plantio. Revista Brasileira de Plantas Medicinais, 5, 7176.

Smet, I. e Beeckman, T. (2011), Asymmetric cell division in land plants and algae: the driving force for differentiation. Nature Reviews Molecular Cell Biology, 12, 177-188.

Stenvall, N.; Piisilä, M.; Pulkkinen, P. (2009), Seasonal fluctuation of root carbohydrates in hybrid aspen clones and its relationship to the sprouting efficiency of root cuttings. Canadian Journal of Forest Research, 39, 1531-1537.

Taiz, L. e Zeiger, E. (2009), Fisiologia vegetal. 4 Ed. Porto Alegre: Artmed, 848p.
Torres, A. G. M. Relação entre sazonalidade, desrama e carboidratos no crescimento do eucalipto na propagação vegetativa por miniestaquia. Dissertação (Mestrado em Recursos Florestais) - Escola Superior de Agricultura "Luiz de Queiroz”, Universidade de São Paulo, 2003.

Trevisam, R. Análises histológicas e bioquímicas em calos de Eucalyptus urophylla S.T. Blake cultivados in vitro sob interação nutricional de boro e cálcio. Tese (Doutorado em Recursos Florestais) - Escola Superior de Agricultura "Luiz de Queiroz”, Universidade de São Paulo, 2005.

Trevisam, R. Atuação de concentrações de boro na morfogênese de Eucalyptus urophylla cultivados in vitro. Dissertação (Mestrado em Fisiologia e Bioquímica de Plantas) - Escola Superior de Agricultura "Luiz de Queiroz", Universidade de São Paulo, 2001.

Veyres, N.; Danon, A.; Aono, M.; Galliot, S.; Karibasappa, Y.B.; Diet, A.; Grandmottet, F.; Tamaoki, M.; Lesur, D.; Pilard, S.; Boitel-Conti, M.; Sangwan-Norreel, B.S.; Sangwan, R.S. (2008), The Arabidopsis sweetie mutant is affected in carbohydrate metabolism and defective in the control of growth, development and senescence. The Plant Journal, 55, 665-686.

Wit Ondas, H. W.; Brondani, G. E.; Figueiredo, C. R. F.; Almeida, C. V.; Almeida, M. Exposição ao frio e análise histológica no enraizamento de miniestacas de Eucalyptus benthamii (2009), In: SIMPÓSIO INTERNACIONAL DE INICIAÇÃO CIENTÍFICA DA UNIVERSIDADE DE SÃO PAULO, 17., 2009, Pirassununga. Anais... Pirassununga: FMVZ. 1 CD-ROM.

Xavier, A.; Wendling, I.; Silva, R. L. (2009), Silvicultura clonal: princípios e técnicas. Viçosa: Editora da UFV, 272p. 